\title{
View point: gaps in the current guidelines for the prevention of Methicillin-resistant Staphylococcus aureus surgical site infections
}

\author{
Kevin T. Kavanagh ${ }^{1 *}$ (D), Said Abusalem ${ }^{2}$ and Lindsay E. Calderon ${ }^{3}$
}

\begin{abstract}
The authors advocate the addition of two preventative strategies to the current United State's guidelines for the prevention of surgical site infections. It is known that Staphylococcus aureus, including Methicillin-resistant Staphylococcus aureus (MRSA), carriers are at a higher risk for the development of infections and they can easily transmit the organism. The carriage rate of Staph. aureus in the general population approximates 33\%. The CDC estimates the carriage rate of MRSA in the United States is approximately $2 \%$. The first strategy is preoperative screening of surgical patients for Staph. aureus, including MRSA. This recommendation is based upon the growing literature which shows a benefit in both prevention of infections and guidance in preoperative antibiotic selection. The second is performing MRSA active surveillance screening on healthcare workers. The carriage rate of MRSA in healthcare workers approximates $5 \%$ and there are concerns of transmission of this pathogen to patients. MRSA decolonization of healthcare workers has been reported to approach a success rate of $90 \%$. Healthcare workers colonized with dangerous pathogens, including MRSA, should be assigned to non-patient contact work areas. In addition, there needs to be implemented a safety net for both the worker's economic security and healthcare. Finally, a reporting system for the healthcare worker acquisition and infections with dangerous pathogens needs to be implemented. These recommendations are needed because Staph. aureus including MRSA is endemic in the United States. Policies regarding endemic pathogens which are to be implemented only upon the occurrence of a facility defined "outbreak" have to be questioned, since absence of infections does not mean absence of transmission. Optimizing these policies will require further research but until then we should error on the side of patient safety.
\end{abstract}

\section{Commentary}

The emergence of multi-drug resistant organisms presents new challenges for the prevention of surgical site infections (SSI). In July of 2017, the CDC issued additional guidance on preventative strategies [1]. However, there remain a number of important gaps in the prevention of spread of Methicillin-resistant Staphylococcus aureus (MRSA) and other multi-drug resistant drug organisms.

There is mounting evidence regarding the importance of assessing the patient's microbiome for improved treatments and prevention of hospital acquired infections [2]. In the future, characterizing a patient's commensal and

\footnotetext{
* Correspondence: kavanagh.ent@gmail.com

${ }^{1}$ Health Watch USA, Somerset, KY, USA

Full list of author information is available at the end of the article
}

pathogenic bacteria may become common place and practical from both an economic and logistical standpoint. Presently, there is readily available technology to at least screen patients and healthcare workers for dangerous pathogens.

Two additional standards should be adopted to prevent SSI: 1) Preoperative screening and decolonization for Staph. aureus, including MRSA in patients and 2) screening and decolonization of MRSA in healthcare workers, along with the implementation of an event reporting system and the development of protocols for financial and healthcare protection.

Screening of Staph. aureus to prevent surgical site infections Staph. aureus is a common pathogen which causes postoperative infections [3]. It has been demonstrated that

(c) The Author(s). 2018 Open Access This article is distributed under the terms of the Creative Commons Attribution 4.0 International License (http://creativecommons.org/licenses/by/4.0/), which permits unrestricted use, distribution, and reproduction in any medium, provided you give appropriate credit to the original author(s) and the source, provide a link to the Creative Commons license, and indicate if changes were made. The Creative Commons Public Domain Dedication waiver (http://creativecommons.org/publicdomain/zero/1.0/) applies to the data made available in this article, unless otherwise stated. 
between 26 to 37\% of patients are Staph. aureus carriers [4-6] and that these carriers have higher rates of SSIs $[3,7]$. Decolonization has been shown to be effective in decreasing Staph aureus SSIs [3, 4, 8].

Although not widely performed in the United States, WHO has recently recommended decolonization of Staph. aureus carriers for the prevention of SSI, with preoperative patient screening to implement this intervention. This is a strong recommendation for cardiothoracic and orthopedic surgery and a moderate conditional recommendation "when feasible" because of costs for other types of surgery [3]. Similar to the United Kingdom's National Health Service, [9] the United States has the financial resources to implement this policy on all surgical patients.

\section{Screening of MRSA to prevent surgical site infections}

In the United States, screening is not routinely performed for Staph. aureus in preoperative patients, and there has even been reluctance to screen for the more resistant form of Staph. aureus, MRSA. A major concern regarding MRSA is the continued progression and spread of antibiotic resistance, with additional resistance developing to vancomycin and other antibiotics. In addition, there is mounting evidence regarding increase virulence through genetic acquisition and expression [10, 11]. However, there has been abundant research regarding the mechanisms of spread and strategies to control the spread of MRSA, along with analysis of the resistance to setting firm standards to stop this epidemic.

In the United States, screening for MRSA fell out of popularity in part due to a study published in JAMA by Harbarth, et al. [12]. However, this study was poorly implemented as antibiotics active against MRSA were not administered to $57 \%$ of patients known to be MRSA carriers preoperatively ( $30 \%$ of the total number of patients). In $31 \%$ of the total patients, the MRSA cultures were not available until after the surgery [12]. However, the data also indicated that MRSA carriers were over 14 times more likely to develop a postoperative MRSA infection than non-carriers (Chi Squire with Yates Correction, $p<0.0001$ ).

Since, the study by Harbarth, et al. [12] was published, Kavanagh, et al. [13] reviewed 19 studies that indicated a beneficial effect of preoperative MRSA screening, 14 studies reached statistical significance. A wide range of patients were studied including patients in intensive care, and those undergoing vascular, orthopedic, gynecologic, gastrostomy, head and neck, and cardiac surgeries. The vast majority of these studies used pre-post designs and had non-concurrent controls; however, the large number of studies that showed positive effects of pre-operative MRSA screening outweighs the effects of random unknown variables in the pre-post studies [13].
Preoperative knowledge of the MRSA status of surgical patients allows for both the proper selection of preoperative antibiotics and in elective surgical patients, implementation of a preoperative decolonization protocol. MRSA carriers are often prophylaxed with vancomycin or teicoplanin as opposed to a cephalosporin. There is evidence that the use of vancomycin in non-MRSA carriers may lead to an increase in post-surgical infections [14]. In addition, Branch-Elliman, et al., concluded that vancomycin usage in cardiac patients was associated with an increased risk of acute kidney injury and concluded that its risks in MRSA negative patients outweighs its benefits [15].

The following studies have focused on MRSA and support the policies for screening for this pathogen:

- MRSA is highly infectious, and carriers have been observed to spread the organism to the environment at a higher rate than those with infections [16].

- It has been observed that 35\% of MRSA colonized patients can contaminate their environment within $33 \mathrm{~h}$ [17] and once contaminated, surfaces may be MRSA culture positive for up to one to two months [18].

- The CDC estimates that the United States' general population has a carrier rate of $2 \%$ [19].

- Multiple studies found a higher carrier rate in healthcare workers. On average, the rate approaches $5 \%[20,21]$.

- Albrich and Harbarth found 79 studies that support the spread of MRSA from healthcare workers to patients [20].

- MRSA carriers are at an increased risk for MRSA infections [22].

- The fatality rate for MSA bloodstream infections approximates 16\% [23].

In the United States, MRSA bloodstream infections are not on track to meeting the 2020 goals of a $50 \%$ reduction, there is some evidence that in 2015 these infections may have even increased [24].

\section{Transmission of staph aureus and MRSA from healthcare workers to patients}

MRSA is endemic in the United States. The CDC estimates that $2 \%$ of the general population are carriers [19] and according to the CDDEP $43 \%$ of outpatient Staph. aureus cultures are oxacillin resistant (2012 data) [25]. So why has there not been more research directed at healthcare worker colonization?

It has been demonstrated that healthcare workers can transmit Staph. aureus to patients. Price JR, et al. demonstrated that out of 25 instances of patient acquisition of Staph. aureus, seven were from healthcare workers [5]. Albrich and Harbarth reviewed 68 articles which performed 
genotyping on colonized and infected healthcare workers and found that $93 \%$ had likely transmission from healthcare worker to patient [20]. And, at least one study has reported a decrease in the incidence of MRSA with the identification and treatment of healthcare workers [26].

There is also no reason to believe that transmission of MRSA will differ between different groups of individuals and would be expected to carry equal risks in the general public, patients and healthcare workers. Cadena, et al. observed that patients who are MRSA carriers and are diabetics, on dialysis, or undergoing surgery are at a higher risk for developing MRSA infections than non-carriers [22]. Unlike, the general public, healthcare workers come into contact with some of the most frail and susceptible individuals and thus, prevention of spread should be imperative.

\section{Protocols for screening and decolonization}

The protocol commonly used for Staph. aureus decolonization is daily body washes with an antiseptic for five days plus an intranasal antibiotic ointment, given three times a day. For MRSA positive patients, $2 \%$ mupirocin is often applied intranasally; for MSSA positive patients, Naseptin Nasal Cream (chlorhexidine hydrochloride 0.1\%; neomycin sulfate $0.5 \%$ ) can be used [27]. Eradication of the MRSA carrier state was achieved in up to $88 \%$ of healthcare workers [20]. Universal decolonization of all patients or healthcare personnel regardless of their carrier state should be avoided because of the potential to spread resistance [3, 28].

Similar to patients, the healthcare worker poses a risk of spreading pathogens to the environment. Healthcare employers should not assign healthcare workers in patient contact areas while they are carriers of dangerous pathogens. We feel this policy should apply to MRSA carriers not only because of the pathogen's resistance to antibiotics but also because of concerns regarding increase virulence $[3,10,11]$.

\section{Health policy decisions}

During the July 2017 Centers for Disease Control and Prevention's Healthcare Infection Control Practices Advisory Committee (HICPAC) meeting, the committee discussed the topic of MRSA control as it relates to healthcare workers. Under consideration was a recommendation to screen healthcare workers during an MRSA outbreak.

\section{Endemic or outbreak}

The occurrence of an "Outbreak" is often used to trigger increased infection control and prevention protocols. However, in the United States, an "outbreak" is often defined as a rate of infections above a facility defined baseline. Thus, daily MRSA infections could theoretically be occurring and neither patients, the health department or oversight agencies would be notified of an outbreak in the facility. It all depends upon how many infections it takes to be greater than the facility defined baseline.

Thus, we should not guide our actions around the non-standardized term of "outbreak". We agree with Albrich and Harbarth [20] whose findings support not restricting screening of MRSA to outbreaks in endemic settings.

There is little doubt that MRSA has become endemic in the United States. The absence of an outbreak does not mean there is absence of exposure or transmission; it does not even mean there have been no infections. Our perspective on MRSA and interventions to mitigate it, need to undergo a transformative paradigm shift.

\section{The healthcare worker}

Many categories of healthcare workers contact patients on multiple types of wards. In addition, the increasing trend of "cross-training" of nurses and the use of temporary nurses to save costs, results in the same personnel being assigned to different types of wards. Thus, policies relating to healthcare workers should be facility wide.

The reason for not adopting protocols for readily identifying and controlling pathogen in healthcare workers may lie in conflict-of-interest in the healthcare industry. Detection and decolonization may have a negative financial impact on institutions. All too often, the healthcare worker is put at risk because well-defined occupational safety and healthcare standards for infection control have not been established. Part of this dilemma is the lack of research. By not investigating, a call to action regarding the healthcare workers, along with the health of patients, has been severely mitigated and the development of effective protocols to reduce post-surgical infection rates have been hampered. At the same time difficult and costly decisions have been avoided.

In addition, the United States does not have a national surveillance system for the tracking of healthcare worker acquisition and infections with dangerous pathogens. This results in cases not being recorded and classified as work related. Healthcare staff will often use sick leave or work while ill. Additionally, there is a concern regarding healthcare workers bringing antibiotic resistant pathogens home to their families. Once MRSA is transmitted into a household environment, without further intervention, it may persist for 2.33 to 8.55 years [29].

\section{Need for better standards}

The lack of effective standards for the protection of healthcare workers is not restricted to MRSA. The Ebola epidemic underscored the inadequacy of hospital preparedness to deal with dangerous pathogens. On Aug 7, 2014, assurances were given to the U.S. House Foreign Affairs Subcommittee that healthcare facilities in the United States are trained in and had protocols in place to handle Ebola [30]. However, by October of that year, 
two healthcare workers became infected and it became evident that safety protocols were inadequate and that only a few special biocontainment facilities in the United States could handle patients with highly contagious diseases.

Although MRSA is not as deadly as Ebola, it is highly infectious. According to the Centers of Disease Control and Prevention (CDC), the number of deaths in the United States from MRSA is at least 11,000 each year and there are over 80,000 severe infections [31]. These statistics demonstrate the urgency of improving practices for the protection of patients and staff from MRSA and other multi-drug resistant pathogens. The hospital cost of treating MRSA patients is between $\$ 3.2$ and $\$ 4.2$ billion [32]. This expenditure demonstrates that improved infection prevention strategies, such as those proposed in this paper, can have direct healthcare dollar savings plus improve performance and reimbursement with CMS's value-based purchasing initiatives.

\section{Policy recommendations}

The following policies should be enacted:

1. The screening of patients and healthcare workers for dangerous pathogens, including MRSA, to mitigate the changes of spread to other patients, staff and the community.

2. Establish a surveillance system for healthcare workers to determine the extent of occupational acquisition and infections of dangerous pathogens, including MRSA.

3. Establish an economic and healthcare safety net for healthcare workers who become infected or colonized with dangerous pathogens, including MRSA.

4. Research to promote effective screening and decolonization of healthcare workers for dangerous pathogens, including MRSA.

5. Assessing the effectiveness of the diverse current practices in the healthcare industry in order to implement standardized prevention strategies, including screening protocols. For example, the comparing of the results of the MRSA prevention protocols in the U.S. Veterans Health Administration's healthcare system with those of private industry [24].

In the United States, increased vigilance is necessary. Data is not available for many types of infections, but for MRSA bloodstream infections the data indicates that they may not be coming under control. Data from the National Healthcare Safety Network indicated that MRSA infections increased between 2014 to 2015 and that we are not on track to meet the national goal of a $50 \%$ reduction in MRSA bloodstream infections by 2020 [24].

\section{Conclusion}

Many now believe that knowledge of a patient's microbiome will one day be essential for the maintenance of good health and may even become a part of a yearly physical exam. Until resources are available to accomplish this, we should at a minimum initiative screening of surgical patients for Staph. aureus, including MRSA. Similar to the United Kingdom's National Health Service, [9] the United States has the resources to implement the WHO recommendations [3] regarding the screening of all surgical patients for Staph. aureus.

The United States also need to implement programs for periodic screening of all healthcare workers, including surgical staff, for the resistant form of Staph. aureus, MRSA. Healthcare workers who are positive should be decolonize and whenever possible assigned to nonpatient contact areas until decolonization is complete. Decolonization of healthcare workers is highly successful with $88 \%$ MRSA eradication [20]. Work reassignment programs need to protect affected worker's job and income status and should be an essential component of the policy.

The gaps we have addressed deserve more research including the risks a colonized healthcare worker poses to patients, the number of healthcare workers exposed and infected occupationally, and the development of effective healthcare worker occupational infectious disease surveillance programs. Nevertheless, current evidence indicates that colonization with dangerous pathogens is a critical issue which has the potential of causing grave harm. The existence of research gaps does not mean we should not act, because not acting is in itself an action. It is our duty to deliver patient centered care of the highest quality and until we know a practice, or an inaction is safe, we must error on the side of patient and healthcare worker safety.

\section{Authors' contributions \\ KTK wrote the first draft of manuscript, LEC and SA revised the manuscript and approved the final submission. All authors read and approved the final manuscript.}

Ethics approval and consent to participate

Not applicable

Consent for publication

The authors give ARIC Consent for publication.

\section{Competing interests}

Dr. Kevin Kavanagh has received partial conference attendance and meeting support from the U.S. Dept. of Health and Human Services, National Quality Forum (NQF), National Patient Safety Foundation (NPSF), The Leapfrog Group and Consumer Union. He has served on the Centers for Medicare and Medicaid Services' Technical Expert Panel for Hospital Acquired Conditions, and most recently on the Strategic Working Group for AHRQ for quality indicators, and AHRQ Health Care Effectiveness and Outcomes Research (HEOR) Study Section. He serves on the NQF Consensus Standards Approval Committee. He is an Associate Editor for the Journal of Patient Safety for which he receives an honorarium. He has a first degree relative who is employed by a state university, and is involved with the development of cancer chemotherapeutic and diagnostic agents. The other authors have no competing interests to declare. 


\section{Publisher's Note}

Springer Nature remains neutral with regard to jurisdictional claims in published maps and institutional affiliations.

\section{Author details}

${ }^{1}$ Health Watch USA, Somerset, KY, USA. ${ }^{2}$ Health Watch USA, University of Louisville, Louisville, KY, USA. ${ }^{3}$ Health Watch USA, Eastern Kentucky University, Richmond, KY, USA.

Received: 21 May 2018 Accepted: 13 September 2018

\section{Published online: 18 September 2018}

\section{References}

1. Berríos-Torres SI, Umscheid CA, Bratzler DW, Leas B, Stone EC, Kelz RR, Reinke CE, Morgan S, Solomkin JS, Mazuski JE, Dellinger EP, Itani KMF, Berbari EF, Segreti J, Parvizi J, Blanchard J, Allen G, Kluytmans JAJW, Donlan R, Schecter WP; Healthcare Infection Control Practices Advisory Committee. Centers for Disease Control and Prevention Guideline for the Prevention of Surgical Site Infection, 2017. JAMA Surg. 2017 May 3. doi: https://doi.org/10. 1001/jamasurg.2017.0904. [Epub ahead of print].

2. Blaser MJ. Missing microbes: how the overuse of antibiotics is fueling our modern plagues. New York: Henry Holt and Company, LLC; 2014.

3. Allegranzi B, Bischoff $P$, de Jonge $S$, Kubilay NZ, Zayed B, Gomes SM, Abbas M, Atema JJ, Gans S, van Rijen M, Boermeester MA, Egger M, Kluytmans J, Pittet D, Solomkin JS; WHO guidelines development group. New WHO recommendations on preoperative measures for surgical site infection prevention: an evidence-based global perspective. Lancet Infect Dis 2016; 16(12):e276-e287. doi: https://doi.org/10.1016/S1473-3099(16)30398-X. Epub 2016 Nov 2. PMID: 27816413

4. Rao N, Cannella B, Crossett LS, Yates AJ Jr, McGough R 3rd. A preoperative decolonization protocol for staphylococcus aureus prevents orthopaedic infections. Clin Orthop Relat Res. 2008;466(6):1343-8. https://doi.org/10. 1007/s11999-008-0225-4 Epub 2008 Apr 11.

5. Price JR, Cole K, Bexley A, Kostiou V, Eyre DW, Golubchik T, Wilson DJ, Crook DW, Walker AS, Peto TEA, Llewelyn MJ, Paul J. Modernising medical microbiology informatics group. Transmission of Staphylococcus aureus between health-care workers, the environment, and patients in an intensive care unit: a longitudinal cohort study based on whole-genome sequencing. Lancet Infect Dis. 2017;17(2):207-14. https://doi.org/10.1016/S14733099(16)30413-3 Epub 2016 Nov 16

6. van Vugt JL, Coelen RJ, van Dam DW, Winkens B, Derikx JP, Heddema ER, Stoot JH. Nasal carriage of Staphylococcus aureus among surgeons and surgical residents: a nationwide prevalence study. Surg Infect. 2015;16(2): 178-82. https://doi.org/10.1089/sur.2014.022 Epub 2015 Mar 31.

7. Weinstein $\mathrm{HJ}$. The relation between the nasal-staphylococcal-carrier state and the incidence of postoperative complications. N Engl J Med. 1959; 260(26):1303-8.

8. Saraswat MK, Magruder JT, Crawford TC, Gardner JM, Duquaine D, Sussman MS, Maragakis LL, Whitman GJ. Preoperative staphylococcus aureus screening and targeted decolonization in cardiac 31-surgery. Ann Thorac Surg. 2017;104(4):1349-56. https://doi.org/10.1016/j.athoracsur.2017.03.018 Epub 2017 Jun 1.

9. Screening for Meticillin-resistant Staphylococcus aureus (MRSA) colonisation. National Health Service. 2006. Accessed on 4 Aug. 2018 from http:// webarchive.nationalarchives.gov.uk/20130124033950/http://www.dh.gov. uk/prod_consum_dh/groups/dh_digitalassets/@dh/@en/documents/ digitalasset/dh_063187.pdf

10. Otto M. Community-associated MRSA: what makes them special? Int J Med Microbiol. 2013;303(6-7):324-30. https://doi.org/10.1016/j.jimm.2013.02.007 Epub 2013 Mar 19

11. Thurlow LR, Joshi GS, Richardson AR. Virulence strategies of the dominant USA300 lineage of community-associated methicillin-resistant Staphylococcus aureus (CA-MRSA). FEMS Immunol Med Microbiol. 2012;65(1):5-22. https://doi. org/10.1111/j.1574-695X.2012.00937.x Epub 2012 Mar 5.

12. Harbarth S, Fankhauser C, Schrenzel J, Christenson J, Gervaz P, BandieraClerc C, Renzi G, Vernaz N, Sax H, Pittet D. Universal screening for methicillin-resistant Staphylococcus aureus at hospital admission and nosocomial infection in surgical patients. JAMA. 2008;299(10):1149-57. https://doi.org/10.1001/jama.299.10.1149.

13. Kavanagh KT, Calderon LE, Saman DM, Abusalem SK. The use of surveillance and preventative measures for methicillin-resistant staphylococcus aureus infections in surgical patients. Antimicrob Resist Infect Control. 2014;3:18 https://doi.org/10.1186/2047-2994-3-18 eCollection 2014

14. Gupta K, Strymish J, Abi-Haidar Y, Williams SA, Itani KM. Preoperative nasal methicillin-resistant Staphylococcus aureus status, surgical prophylaxis, and risk-adjusted postoperative outcomes in veterans. Infect Control Hosp Epidemiol. 2011:32:791-6.

15. Branch-Elliman W, Ripollone JE, O'Brien WJ, Itani KMF, Schweizer ML, Perencevich E, Strymish J, Gupta K. Risk of surgical site infection, acute kidney injury, and Clostridium difficile infection following antibiotic prophylaxis with vancomycin plus a beta-lactam versus either drug alone: A national propensity-score-adjusted retrospective cohort study. PLoS Med. 2017;14(7):e1002340. https://doi.org/10.1371/journal.pmed. 1002340 eCollection 2017 Jul.

16. Knelson LP, Williams DA, Gergen MF, Rutala WA, Weber DJ, Sexton DJ, Anderson DJ. Centers for Disease Control and Prevention epicenters program. A comparison of environmental contamination by patients infected or colonized with methicillin-resistant Staphylococcus aureus or vancomycin-resistant enterococci: a multicenter study. Infect Control Hosp Epidemiol. 2014;35(7):872-5. https://doi.org/10.1086/676861 Epub 2014 May 7.

17. Chang S, Sethi AK, Stiefel U, et al. Occurrence of skin and environmental contamination with methicillin-resistant Staphylococcus aureus before results of polymerase chain reaction at hospital admission become available. Infect Control Hosp Epidemiol. 2010;31:607Y612.

18. Neely AN, Maley MP. Survival of enterococci and staphylococci on hospital fabrics and plastic. J Clin Microbiol. 2000;38(2):724-6.

19. General Information About MRSA in the Community. Centers for Disease Control and Prevention. Mar. 25, 2018. Last accessed on 20 Jul 2018 from https://www.cdc.gov/mrsa/community/index.html

20. Albrich WC, Harbarth S. Health-careworkers: source, vector, or victim of MRSA. Lancet infect. Dis. 2008;8:289-301.

21. Sassmannshausen $R$, Deurenberg RH, Köck R, Hendrix $R$, Jurke $A$, Rossen JW, Friedrich AW. MRSA prevalence and associated risk factors among healthCare Workers in non-outbreak Situations in the Dutch-German EUREGIO. Front Microbiol. 2016;7:1273. https://doi.org/10.3389/fmicb.2016.01273 eCollection 2016.

22. Cadena J, Thinwa J, Walter EA, Frei CR. Risk factors for the development of active methicillin-resistant Staphylococcus aureus (MRSA) infection in patients colonized with MRSA at hospital admission. Am J Infect Control. 2016:44(12):1617-21. https://doi.org/10.1016/j.ajic.2016.05.009 Epub 2016 Jun 29

23. Ayau P, Bardossy AC, Sanchez G, Ortiz R, Moreno D, Hartman P, Rizvi K, Prentiss TC, Perri MB, Mahan M, Huang V, Reyes K, Zervos MJ. Risk factors for 30-day mortality in patients with methicillin-resistant Staphylococcus aureus bloodstream infections. Int J Infect Dis. 2017;61:3-6. https://doi.org/10.1016/ j.ijid.2017.05.010 Epub 2017 May 19.

24. Kavanagh KT, Abusalem S, Calderon LE. The incidence of MRSA infections in the United States: is a more comprehensive tracking system needed? Antimicrob Resist Infect Control. 2017;6:34. https://doi.org/10.1186/s13756017-0193-0 eCollection 2017

25. Resistance of Staphylococcus aureus to Oxacillin \{MRSA\}. Resistance Map. Center for Disease Dynamics, Economics \& Policy (CDDEP). 2012 Data. Accessed on 20 Jul 2018 from https://resistancemap.cddep.org/ AntibioticResistance.php

26. Ben-David D, Mermel LA, Parenteau S. Methicillin-resistant Staphylococcus aureus transmission: the possible importance of unrecognized health care worker carriage. Am J Infect Control. 2008;36(2):93-7. https://doi.org/10. 1016/j.ajic.2007.05.013.

27. Dancer SJ, Christison F, Eslami A, Gregori A, Miller R, Perisamy K, Robertson C, Graves N. Is it worth screening elective orthopaedic patients for carriage of Staphylococcus aureus? A part-retrospective case-control study in a Scottish hospital. BMJ Open. 2016;6(9):e011642. https://doi.org/10.1136/ bmjopen-2016-011642.

28. Naparstek L, Carmeli Y, Chmelnitsky I, Banin E, Navon-Venezia S. Reduced susceptibility to chlorhexidine among extremely-drug-resistant strains of Klebsiella pneumoniae. J Hosp Infect. 2012;81(1):15-9. https://doi.org/10. 1016/j.jhin.2012.02.007 Epub 2012 Mar 30.

29. Alam MT, Read TD, Petit RA 3rd, Boyle-Vavra S, Miller LG, Eells SJ, Daum RS, David MZ. Transmission and microevolution of USA300 MRSA in U.S. households: evidence from whole-genome sequencing. MBio. 2015;6(2): e00054. https://doi.org/10.1128/mBio.00054-15 PMC4453535. 
30. Statement of Tom Frieden, MD, MPH, Director, Centers for Disease Contro and Prevention. House Committee on Foreign Affairs, Subcommittee on Africa, Global Health, Global Huma rights, and international organizations combating the Ebola threat. August 7, 2014.

31. Frieden T. Antibiotic Resistance Threats in the United States, 2013. Centers for Disease Control and Prevention. Apr. 23, 2013. Accessed on 4 Aug 2018 from https://www.cdc.gov/drugresistance/threat-report-2013/pdf/ar-threats2013-508.pdf

32. MRSA: A Deadly Pathogen with Fewer and Fewer Treatment Options. Pew Charitable Trusts. April 3, 2012. Accessed on 3 Aug 2018 from http://www. pewtrusts.org/en/research-and-analysis/issue-briefs/2012/04/03/mrsa-adeadly-pathogen-with-fewer-and-fewer-treatment-options

Ready to submit your research? Choose BMC and benefit from:

- fast, convenient online submission

- thorough peer review by experienced researchers in your field

- rapid publication on acceptance

- support for research data, including large and complex data types

- gold Open Access which fosters wider collaboration and increased citations

- maximum visibility for your research: over $100 \mathrm{M}$ website views per year

At BMC, research is always in progress.

Learn more biomedcentral.com/submissions 